\title{
MARKETING E TERRITÓRIO NO ENSINO SUPERIOR
}

\author{
Leandro Xavier Timóteo ${ }^{1}$ \\ Maria Celeste Reis Fernandes de Souza ${ }^{2}$ \\ Renata Bernardes Faria Campos ${ }^{3}$
}

RESUMO: Neste artigo foi discutido acerca do marketing direcionado por abordagem territorial e como é possível, por meio dele, construir e divulgar instituições de ensino superior diferenciadas, identificando os desejos e as necessidades de potenciais estudantes e desenvolvendo produtos e serviços melhores para atender às demandas. Diante disso, o objetivo deste artigo foi mapear a produção bibliográfica nos últimos dez anos sobre marketing e território no ensino superior. Para isso, foi realizada uma busca sistemática realizada no portal de periódicos da Capes. Foram considerados artigos revisados por pares, publicados nos últimos io anos na língua portuguesa, que continham os termos "Marketing, território" e "Ensino Superior”. Dos 66 artigos encontrados, 2I foram selecionados para revisão sistemática. Os demais não possuíam relação direta com a busca, pois não abordavam temas relacionados a marketing, território e ensino superior. Com o aumento do acesso ao Ensino Superior decorrente do crescimento da oferta do ensino na modalidade à distância, as ações de marketing se tornaram primordiais para a captação e manutenção dos estudantes. As redes sociais foram utilizadas como ferramenta para ampliarem as informações e conhecimento sobre as ofertas. À vista disso, é muito importante que as instituições estruturem ações para atingir o público-alvo.

Palavras-chave: Marketing. Território. Ensino Superior.

ABSTRACT: In this article it was discussed about marketing directed by territorial approach and how it is possible, through it, to build and advertise differentiated higher education institutions, identifying the desires and needs of potential students and developing better products and services to meet demands. In view of this, the objective of this article was to map the bibliographic production in the last ten years on marketing and territory in higher education. To this end, a systematic search was carried out on the Capes periodicals portal. We considered peer-reviewed articles, published in the last ro years in Portuguese, that contained the terms "Marketing, territory" and "Higher Education". Of the 66 articles found, 2i were selected for systematic review. The others were not directly related to the search because they did not address topics related to marketing, territory, and higher education. With the

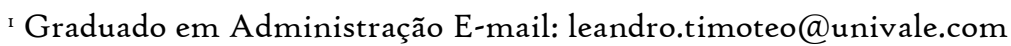

${ }^{2}$ Graduada em pedagogia mestre em ciências e doutora em educação. E-mail: maria.celeste@univale.com.

${ }^{3}$ Graduação em biologia mestrado e doutorado em entomologia E-mail: Renata.campos@univale.com
} 
increase in access to higher education due to the growth of distance learning, marketing actions have become essential to attract and keep students. Social networks have been used as a tool to broaden information and knowledge about the offers. In view of this, it is very important that institutions structure actions to reach their target audience.

Keywords: Marketing. Territory. Higher Education.

\section{INTRODUÇÃO}

O Brasil, tem apresentado crescente número na abertura de novas instituições de ensino superior privadas (IES). Nos últimos io anos, o INEP (Instituto Nacional de Estudos e Pesquisas Educacionais Anísio Teixeira) registrou o aumento de Io,27\% de credenciamento para a inauguração de novas IES. Em contrapartida, segundo o órgão governamental, o número de matrículas diminuíram 45,4\%, apesar de muito incentivada por politicas públicas, como FIES e PROUNI (INEP, 2019).

O FIES e o PROUNI são Programas de cunho econômico-social, que buscam alcançar jovens de baixa renda que não podem custear a graduação ou não possuem condições de se deslocar para universidades federais, localizadas nos grandes centros do país. Nesse cenário, a entrada de brasileiros no ensino superior não atinge o parâmetro internacional. Evidenciando, as falhas das IES em se comunicar com os alunos, embora tenha recebido o apoio governamental para integrar todos os públicos (INEP, 2019).

Nessa perspectiva, admite-se a necessidade do marketing com abordagem territorial direcionada. Por conseguinte, as IES carecem identificar as necessidades dos potenciais estudantes, e seus respectivos desejos esperados ao ingressar em uma universidade. Alicerçado nessas questões as instituições devem desenvolver estratégias e produtos para atender às demandas do corpo social.

À vista disso, precisamos discutir a definição da palavra marketing, a qual no dicionário Oxford Languages está descrita como: 
Estratégia empresarial de otimização de lucros por meio da adequação da produção e oferta de mercadoria ou serviços às necessidades e preferências dos consumidores, recorrendo a pesquisas de mercado, design e campanhas publicitárias etc.

Em outras palavras, é a busca pelas organizações em suprir as necessidades e desejos de seus consumidores e partes interessadas (COSTA et al., 2014).

Ademais, o território é também de extrema importância nesse processo, isso porque o território define quem é o estudante, condição econômica, grau de escolaridade, quais são as suas necessidades, etc. Toda abordagem territorial tem como objetivo dar um rosto para a comunidade que ali vive, identificando suas carências e seus anseios.

Dessa maneira, quando se trata de entregar valor para um segmento de mercado, deve-se focar nos aspectos intangíveis do processo de troca, de tal modo a proporcionar uma melhor interatividade entre as organizações e seus potenciais consumidores (DUARTE et al., 2018).

Com base nessas reflexões, o artigo apresentado tem o intuito de fundamentar os benefícios da aplicação dos princípios de marketing para o desenvolvimento das instituições de ensino superior privadas brasileiras. Nesse contexto, é evidente que as organizações de ensino superior precisam implantar e efetivar planos de marketing como prática gerencial (GOMES et al., 2013).

Diante disso, este trabalho empenhou-se em mapear a produção bibliográfica nos últimos dez anos sobre marketing e território no ensino superior.

\section{METODOLOGIA}

A pesquisa foi realizada por meio de pesquisa bibliográfica sistemática, com levantamentos de informações no Portal de Periódicos da Coordenação de Aperfeiçoamento de Pessoal de Nível Superior (CAPES) utilizando os descritores "marketing”, "território", "ensino superior”, considerando o período dos últimos io anos, e como filtro de seleção o idioma português. Os autores utilizados na fundamentação dos argumentos apresentados foram: Washigton José, Nila Patricia, 
Fábio Rezende, Valdi de Lima, Lylia Maria, Ahiram B. C. De Castro, Helena Alves, Mario Raposo, Emersom W., Asillam Costa, Roseli Oliveira, Fábio Vinicius Giancarlo Gomes, Amélia Silveira, Maria José B., Eduardo L., Silvio A. Minciotti, F. Malvezzi, A. Zambalde, Valmir lemos, José Erimar dos Santos, Ismaria Pereira de Souza, Adriana R. W., Sérgio B. Elder S., Mônica Maur G., Teresa Costa, Ana Maria, Tânia Fraga, Dina Mieagaia, Pedro G. Carvalho, Paula J.L., Henrique A.L.S., Marcelo Romani, Aline dos Santos, Siemos W., André M. T. da Silva, Miriam Pires E., Carlos Osmar B., Rafael Alcadipani da S., Mariane Lemos Lourenço, Dinara Calazans, Washigton José, Nila Patrícia, Fábio Rezende e Valdi de Lima

\section{RESULTADO}

Após análise de todos os artigos referenciados, os quais foram selecionados e organizados no quadro abaixo. Foi possível constatar, por meio do estudo quantitativo, que primeiro deve ser estudado o território de eventual atuação da instituição de ensino superior, em seguida identificar os consumidores e suas necessidades, logo se adequar a esse perfil e produzir estratégias de marketing direcionadas a esse público. Com essa abordagem, as chances de atingir um potencial consumidor é consideravelmente maior, comparado às práticas antigas de marketing das IES. Outro ponto identificado é a importância do monitoramento constante do comportamento da sociedade, afinal ele reflete diretamente no mercado consumidor. A tabela abaixo apresenta os artigos que foram estudados e algumas de suas caraterísticas.

Tabela I: Características dos artigos em estudo

\begin{tabular}{|c|c|c|c|c|}
\hline Tema & Autor & $\begin{array}{c}\text { Ano de } \\
\text { publicação }\end{array}$ & Tipo de estudo & Objetivo \\
\hline Território & $\begin{array}{c}\text { Teresa Costa } \\
\text { Silva }\end{array}$ & 2oro & $\begin{array}{c}\text { Revisão } \\
\text { bibliográfica }\end{array}$ & $\begin{array}{c}\text { Facilitar o } \\
\text { acesso a } \\
\text { pesquisas, } \\
\text { publicando em } \\
\text { único site. }\end{array}$ \\
\hline
\end{tabular}




\begin{tabular}{|c|c|c|c|c|}
\hline Tema & Autor & $\begin{array}{c}\text { Ano de } \\
\text { publicação }\end{array}$ & Tipo de estudo & Objetivo \\
\hline & $\begin{array}{l}\text { Ana Maria } \\
\text { Tânia Fraga }\end{array}$ & 2013 & $\begin{array}{c}\text { Revisão } \\
\text { bibliográfica }\end{array}$ & $\begin{array}{l}\text { Evolução do } \\
\text { ensino superior } \\
\text { ao longo dos } \\
\text { anos }\end{array}$ \\
\hline & $\begin{array}{c}\text { Dina Mieagaia } \\
\text { Pedro G. } \\
\text { Carvalho }\end{array}$ & 2012 & $\begin{array}{c}\text { Análise de } \\
\text { dados }\end{array}$ & $\begin{array}{c}\text { Monitorar e } \\
\text { avaliar a } \\
\text { empregabilidad } \\
\text { e dos } \\
\text { graduandos em } \\
\text { Portugal }\end{array}$ \\
\hline & $\begin{array}{c}\text { Paula J.L. } \\
\text { Henrique } \\
\text { A.L.S. }\end{array}$ & 2015 & $\begin{array}{c}\text { Revisão } \\
\text { bibliográfica }\end{array}$ & $\begin{array}{l}\text { Juventude e o } \\
\text { ensino superior } \\
\text { integrados na } \\
\text { educação } \\
\text { ambiental }\end{array}$ \\
\hline & $\begin{array}{c}\text { Marcelo } \\
\text { Romani } \\
\text { Aline dos } \\
\text { santos } \\
\text { Siemos W. }\end{array}$ & 2018 & $\begin{array}{c}\text { Revisão } \\
\text { bibliográfica }\end{array}$ & $\begin{array}{c}\text { Como está a } \\
\text { pesquisa } \\
\text { acadêmica } \\
\text { sobre GI? }\end{array}$ \\
\hline & $\begin{array}{c}\text { André M. T. } \\
\text { da Silva } \\
\text { Mariane } \\
\text { Lemos } \\
\text { Lourenço }\end{array}$ & 2018 & $\begin{array}{c}\text { Revisão } \\
\text { bibliográfica }\end{array}$ & $\begin{array}{c}\text { Como os } \\
\text { docentes } \\
\text { interpretam a } \\
\text { cultura } \\
\text { organizacional } \\
\text { das IES }\end{array}$ \\
\hline Marketing & $\begin{array}{c}\text { Miriam Pires } \\
\text { E. } \\
\text { Carlos Osmar } \\
\text { B. } \\
\text { Rafael } \\
\text { Alcadipani da } \\
\text { S. }\end{array}$ & 2013 & $\begin{array}{c}\text { Revisão } \\
\text { bibliográfica }\end{array}$ & $\begin{array}{c}\text { Influência do } \\
\text { método usado } \\
\text { pelo USA no } \\
\text { curso de } \\
\text { ADM. no } \\
\text { Brasil }\end{array}$ \\
\hline
\end{tabular}




\begin{tabular}{|c|c|c|c|c|}
\hline Tema & Autor & $\begin{array}{c}\text { Ano de } \\
\text { publicação }\end{array}$ & Tipo de estudo & Objetivo \\
\hline & $\begin{array}{c}\text { Dinara } \\
\text { Calazans } \\
\text { Washigton } \\
\text { José } \\
\text { Nila Patricia } \\
\text { Fábio Rezende } \\
\text { Valdi de Lima }\end{array}$ & 2019 & $\begin{array}{c}\text { Revisão } \\
\text { bibliográfica e } \\
\text { análise } \\
\text { diagnóstica }\end{array}$ & $\begin{array}{l}\text { O motivo da } \\
\text { estagnação das } \\
\text { matrículas do } \\
\text { curso de } \\
\text { administração }\end{array}$ \\
\hline & $\begin{array}{c}\text { Lylia Maria } \\
\text { Ahiram B. C. } \\
\text { De Castro }\end{array}$ & 2014 & $\begin{array}{c}\text { Revisão } \\
\text { bibliográfica e } \\
\text { análise } \\
\text { diagnóstica }\end{array}$ & $\begin{array}{c}\text { Educação não } \\
\text { formal, } \\
\text { conhecimento } \\
\text { como } \\
\text { estratégia e } \\
\text { invocação }\end{array}$ \\
\hline Marketing & $\begin{array}{l}\text { F. Malvezzi } \\
\text { A. Zambalde }\end{array}$ & 2013 & $\begin{array}{c}\text { Revisão } \\
\text { bibliográfica }\end{array}$ & $\begin{array}{l}\text { Abordagem de } \\
\text { marketing no } \\
\text { processo de } \\
\text { inovação } \\
\text { tecnológica }\end{array}$ \\
\hline \multirow{4}{*}{$\begin{array}{c}\text { Marketing e } \\
\text { IES }\end{array}$} & $\begin{array}{l}\text { Helena Alves } \\
\text { Mario Raposo } \\
\text { Emersom W. }\end{array}$ & 2010 & $\begin{array}{c}\text { Revisão } \\
\text { bibliográfica e } \\
\text { análise } \\
\text { diagnóstica }\end{array}$ & $\begin{array}{c}\text { Os impactos } \\
\text { do marketing } \\
\text { das IES }\end{array}$ \\
\hline & $\begin{array}{l}\text { Asillam Costa } \\
\text { Roseli Oliveira } \\
\text { Fábio Vinicius }\end{array}$ & 2014 & $\begin{array}{c}\text { Estudo } \\
\text { quantitativo }\end{array}$ & $\begin{array}{l}\text { Lealdade dos } \\
\text { alunos com as } \\
\text { IES }\end{array}$ \\
\hline & $\begin{array}{c}\text { Giancarlo } \\
\text { Gomes } \\
\text { Amélia } \\
\text { Silveira } \\
\text { Maria José B. }\end{array}$ & 2013 & $\begin{array}{c}\text { Revisão } \\
\text { bibliográfica e } \\
\text { análise } \\
\text { diagnóstica }\end{array}$ & $\begin{array}{l}\text { Analisar o } \\
\text { plano de } \\
\text { marketing em } \\
\text { IES na região } \\
\text { Sul do Brasil }\end{array}$ \\
\hline & $\begin{array}{l}\text { Eduardo L. } \\
\text { Silvio A. } \\
\text { Minciotti }\end{array}$ & 2017 & $\begin{array}{c}\text { Revisão } \\
\text { bibliográfica }\end{array}$ & $\begin{array}{l}\text { Evolução do } \\
\text { marketing das } \\
\text { IES na região } \\
\text { da Grande } \\
\text { ABC paulista }\end{array}$ \\
\hline
\end{tabular}




\begin{tabular}{|c|c|c|c|c|}
\hline Tema & Autor & $\begin{array}{c}\text { Ano de } \\
\text { publicação }\end{array}$ & Tipo de estudo & Objetivo \\
\hline & $\begin{array}{c}\text { Valmir lemos } \\
\text { José Erimar } \\
\text { dos Santos }\end{array}$ & 2014 & $\begin{array}{c}\text { Revisão } \\
\text { bibliográfica }\end{array}$ & $\begin{array}{l}\text { Refletir sobre a } \\
\text { presença e } \\
\text { influência das } \\
\text { redes sociais na } \\
\text { educação }\end{array}$ \\
\hline & $\begin{array}{c}\text { Ismaria Pereira } \\
\text { de Souza }\end{array}$ & 2021 & $\begin{array}{c}\text { Análise de } \\
\text { dados }\end{array}$ & $\begin{array}{l}\text { Analisar as } \\
\text { percepções de } \\
\text { estudantes de } \\
\text { graduação } \\
\text { sobre os } \\
\text { fatores do } \\
\text { marketing } \\
\text { educacional }\end{array}$ \\
\hline $\begin{array}{c}\text { Marketing e } \\
\text { IES }\end{array}$ & $\begin{array}{c}\text { Adriana R. W. } \\
\text { Sérgio B. Elder } \\
\text { S. Môn ica } \\
\text { Maur G. }\end{array}$ & 2017 & $\begin{array}{c}\text { Revisão } \\
\text { bibliográfica e } \\
\text { análise } \\
\text { diagnóstica }\end{array}$ & $\begin{array}{c}\text { Investigar a } \\
\text { influência das } \\
\text { capacidades } \\
\text { dinâmicas no } \\
\text { desempenho } \\
\text { organizacional } \\
\text { e o papel das } \\
\text { capacidades do } \\
\text { marketing } \\
\text { como } \\
\text { mediador nas } \\
\text { IES }\end{array}$ \\
\hline
\end{tabular}

Fonte: Elaboração Propria. (2021)

Em um primeira análise, é possível observar que os estudos voltados para o marketing relacionado às instituições de ensino são precários e com pouca base de dados. Recapitulando o conceito de marketing explicitado acima é constatado que o marketing das IES já existe há muitos anos, entretanto não possui a devida atenção.

Nesse sentido, é necessário que as instituições de ensino avaliem a mudança no comportamento da sociedade, e se adaptem às novas formas de ensino, com o objetivo de comunicar melhor com seus alunos. Além disso, é preciso que mais estudos sejam publicados e mais dados sejam coletados, para que as instituições de ensino superior acompanhem a evolução do comportamento de seus consumidores. 
Por outro ângulo, notamos que há uma enorme carência em abordagens territoriais analisadas, apesar do marketing das IES serem pouco explorados, algumas regiões do Brasil necessitam de grande atenção das universidades, as quais são possivelmente atendidas a partir do meio digital e das novas formas de ensino. Dessa forma, é recomendado identificar as áreas propícias, as quais possuem ausência do ensino superior tradicional e são possivelmente preenchidas com as novas formas de ensino. Logo a captação de clientes por meio do marketing direcionado das IES serão extremamente lucrativos.

Por fim, notamos que, após uma minuciosa leitura e análise de dados sobre marketing, é imprescindível acompanhar as mudanças da sociedade, afinal o marketing é feito para chamar a atenção das pessoas, as quais estão inseridas em um contexto histórico e sociocultural. Sendo assim, é dever das IES adaptar os cursos oferecidos ao novo modelo de consumo.

Baseado nos estudos bibliográficos realizados, é executável discorrer sobre marketing no ensino superior em forma de estudo aplicado. Sendo assim, vale abordar, de início que um dos grandes desafios para as instituições de ensino para os próximos anos será a identificação e a disponibilização de recursos informacionais para atender melhor a demanda de diferentes públicos específicos (MATTOS; FRAGA, 2013).

Certamente, a abordagem territorial merece atenção ano após ano. Além disso, as organizações devem se preocupar em adquirir e disseminar conhecimentos que estejam alinhados à sua estratégia, pois somente assim será possível viabilizar tecnologias e ideias e produzir inovação a partir dos conhecimentos adquiridos (BRITO; CASTRO, 2014).

Nesse contexto, as instituições precisam estar atentas às tendências do mercado e gerar inovações, envolvendo a comunidade de seu território e oferecendo não somente a formação acadêmica, como também ser um agente de responsabilidade social e mudança de paradigmas junto à sociedade.

De acordo com Fiorillo (2015), quatro competências organizacionais são fundamentais para quem uma instituição obtenha vantagem competitiva: Gestão de 
Avaliação de Curso, Gestão Estratégica e de Políticas para a EAD, Gestão de Recursos Humanos e Equipe Multidisciplinares, e Gestão e Planejamento da Infraestrutura Física e Tecnológica.

Entretanto, o papel das instituições devem ir além das salas de aulas. Para Calazans et al. (2019), a atividade de extensão possui o papel de elo integrador entre a pesquisa e o ensino e possibilita a construção de uma proposta interdisciplinar unificada que reconhece a educação como uma prática emancipatória e contínua do ser humano.

Dessa forma, as IES devem estar atentas à todos que integram a comunidade de ensino superior, se mostrarem dispostas e acessíveis para o corpo social. Posto isso, a questão dos recursos humanos é um aspecto importante a cosiderar. Silva e Lourenço (2018), argumentam que atualmente, ocorre uma precarização do trabalho docente, que é tratado como um mero executor de programas de ensino não tem sua autonomia reconhecida, sendo esta prática vista por muitas instituições de ensino como forma de agradar os clientes e o mercado de atuação.

Contudo, é preciso buscar um equilíbrio entre as demandas de mercado e a atuação do corpo docente, de modo que a autonomia destes profissionais seja garantida, mas que seja fomentada a inovação e o intraempreendedorismo para atender às demandas do mercado.

Nessa conjuntura, para Boaventura et al. (2018), a interdisciplinaridade é o fator que tem movido às instituições de ensino na busca de uma formação que desenvolva habilidades versáteis e ajustadas a um mercado de trabalho dinâmico e instável. Todavia, isto é uma exceção no Brasil, visto que a maior parte das disciplinas são aplicadas sem o cuidado em articular conteúdos de áreas distintas, oferecendo um conhecimento personalizado e adaptado às condições do momento.

Não obstante, estamos em uma realidade com mudanças sucessivas, tendências globais fundamentadas em sistemas políticos, defensores da economia de mercado Dessa forma, é difícil que se alcance uma sã concorrência e competitividade entre os vários agentes econômicos e sociais sem o papel fundamental das instituições de 
ensino superior dando importância ao conhecimento de mercado aliado ao conhecimento científico. Sendo assim, é indubitável a existência de fortes argumentos para que as instituições de ensino reconheçam o potencial do marketing, como filosofia orientadora da sua gestão. Esta realidade traz benefícios à própria instituição, através do alcance dos seus objetivos e da realização da sua missão e beneficia seu públicoalvo, por meio de um nível mais elevado de satisfação (ALVES et al., 2oro).

Mais uma vez se reforça o ponto de que a atuação do corpo docente é fundamental para as ações de marketing da instituição, visto que dentro da sala de aula, os professores, com a qualidade do ensino que proporcionam, podem contribuir para que os alunos se tornem agentes captadores e importantes multiplicadores de uma reputação positiva para as instituições de ensino.

Diante disso, é importante que as ações de marketing estejam alinhadas com o público alvo da IES e com sua área de atuação. Nesse cenário, segundo Takahashi et al. (2017) o marketing exerce uma importante função na sobrevivência, crescimento e renovação da oferta de serviços educacionais para as instituições de ensino e no desempenho organizacional destas. $O$ setor de ensino superior, no contexto brasileiro, tem participado de um ambiente competitivo que se dá agora em um nível diferente, profissionalizado, que exige conhecimentos profissionais e práticas de marketing.

Entretanto, este é um fenômeno relativamente recente no Brasil, onde em poucas décadas não foram verificadas muitas mudanças, as quais haviam pouca diversificação e competição. Por esse ângulo, Segundo Linzmayer e Minciotti (2017), a utilização do marketing educacional como ferramenta estratégica, assegura o crescimento e aumento da eficiência educacional das instituições de ensino. Destacam ainda que, profissionais de marketing que atuam também no corpo docente das instituições de ensino superior, ajudam na identificação de pontos fortes e fracos, assim como a implementação e o aprimoramento das ações e atividades referentes a estes serviços.

Considerando as mudanças ocorridas nos últimos anos, os autores citados constataram que as instituições de ensino vêm se preocupando cada vez mais em 
buscar o reposicionamento de seus produtos e serviços, assim como novas formas de relacionamento com seus clientes e consumidores.

Essas inovações influenciam positivamente na qualidade do ensino, o que tem levado as instituições a priorizar melhorias nos processos de comunicação, desenvolvendo novos canais de contato entre clientes e fornecedores, além dos serviços de suporte, que agilizam e ampliam os serviços prestados (GUIMARÃES et al., 2013). Ademais, para Costa et al. (2014), investir em uma filosofia de marketing de relacionamento é de suma importância para estabelecer uma relação entre as instituições de ensino e seus alunos. A satisfação do aluno é um grande diferencial para a escolha das instituições de ensino e um dos elementos necessários para a retenção e lealdade na educação do ensino superior.

No que diz respeito à organização das estratégias de marketing, os autores referenciados trazem a ideia de que a forma com que os clientes são tratados pelas instituições é a principal responsável pelo sucesso dos planos de ação. Isso passa desde as formas de acesso ao ensino até o modo com que os alunos são acolhidos no ambiente educacional, incluindo todas os setores da organização, não somente a sala de aula.

Atentando-se a isso, o objetivo do marketing das IES é aproximar os alunos das instituições, e para que isso aconteça, a comunicação deve ser equivalente, um exemplo claro disso são as redes sociais, afinal é la que os estudantes estão. Posto isso, os setores administrativos das instituições de ensino possuem muita relevância para o alcance da percepção de qualidade e confiança do aluno na instituição. De acordo com Santos e Santos (2014), as redes sociais influenciam na organização política dos cidadãos quanto à luta por melhorias sociais; na maneira de perceber o espaço-tempo-atual; na concepção de autonomia e de vivência; no consumo; na aquisição do conhecimento, bem como no processo de ensino e aprendizagem, fenômenos que precisam ser pensados, sobretudo pelas instituições de ensino.

Depois de traçar todo o comportamento do público alvo com o posicionamento da IES, é possível chegar ao panorama de que estratégias e produtos devem ser utilizados pela instituição. Analisando os arquivos, referenciados nesse artigo, é 
identificado a lacuna na relação entre curso superior e a garantia da empregabilidade estável.

Perante o exposto, os artigos tratavam de questões relacionadas a empregabilidade dos estudantes, as formas de disseminação do conhecimento, a estrutura organizacional e os fatores que influenciam na qualidade do ensino superior, a sustentabilidade como uma estratégia de competitividade e possíveis estratégias para a divulgação do trabalho de instituições de ensino superior.

Nesse contexto, a empregabilidade dos egressos é um ponto importante a ser considerado pelas instituições de ensino ao planejarem suas ações de marketing. De acordo com Miragaia e Carvalho (2012) e Rowe et al. (2011), é importante promover o engajamento dos estudantes para com a carreira, de modo que ele busque se adaptar ao mercado de trabalho com um perfil inovador. O sucesso dos ex-alunos é um indicador de qualidade das instituições de ensino e elas devem buscar aprimorar esta questão junto aos estudantes.

Outro fator importante para Miragaia e Carvalho (2012) é que faltam metodologias para avaliação da empregabilidade dos egressos das instituições de ensino $e$ isto representa uma grande lacuna para o desenvolvimento da competitividade destas organizações, visto que o mercado tem se tornado cada vez mais exigente e as instituições de ensino devem se preparar para satisfazer essas demandas.

À vista disso, torna-se necessário fortificar o engajamento com a carreira profissional dos professores universitários como forma de buscar inovações e maior qualidade no ensino, o que influencia diretamente no marketing das instituições, visto que os estudantes são os maiores captadores de novos alunos (ROWE et al., 20II).

Outro fator importante, é a imagem que o estudante da IES passa para o mercado de trabalho, ter uma imagem confiável e de referência no mercado fazem a total diferença diante à sociedade. Isso porque, será criado a relação em que estar matriculado em determinada universidade será garantia de empregabilidade. Nesse cenário, Programas de empreendedorismo, segundo Imaginário et al. (2017) podem ser 
uma estratégia interessante para a promoção do desenvolvimento de competências na área do empreendedorismo por meio da criação e gestão de miniempresas por parte dos estudantes.

Uma estratégia que tem gerado diferencial competitivo, segundo Vale et al. (2013), é o processo de americanização do ensino, principalmente na área de administração e engenharia. Este processo de difusão do modelo norte-americano de administração tem gerado um diferencial competitivo, já adotado por instituições brasileiras, como a Fundação Getúlio Vargas e a Universidade de São Paulo.

Portanto, a extensão é uma importante forma de as instituições de ensino promoverem a integração com a sociedade, a disseminação do conhecimento, a promoção da interdisciplinaridade e o preparo de seus estudantes para o mercado de trabalho. Colocando os estudantes em contato direto com a prática do mercado, mesclando as formas de aprendizado.

Diante de tudo exposto, é indubitável que as IES devem adotar o marketing mais agressivo, desde que esteja preparada para receber os alunos vindos das ações.

\section{CONCLUSÃO}

Os aspectos mais frequentes abordados nos artigos analisados foram a empregabilidade, a ação social, as ferramentas de ensino à distância e disseminação da informação, a interdisciplinaridade, a extensão, a inovação e a sustentabilidade como estratégias de marketing. $O$ uso das redes sociais também foi citado como uma importante ferramenta para a disseminação de conhecimento e divulgação dos trabalhos das instituições de ensino em diferentes regiões.

Outro aspecto relevante identificado na pesquisa foi o trabalho de marketing com os estudantes, pois estes são os maiores captadores de novos clientes para as instituições de ensino. Isto pode ser efetivado diante de estratégias internas para a gerar a satisfação do aluno, envolvendo todos os setores das instituições de ensino.

Embora os trabalhos tenham sido realizados sob o recorte de um território, a abordagem territorial, na maioria dos casos, foi utilizada apenas para a delimitação da 
área de estudo, sem que fosse realizada uma correlação mais profunda entre a realidade do território e a pesquisa. Independente disso, é notória as lacunas presentes entre o marketing e as instituições de ensino brasileiras.

\section{REFERÊNCIAS}

ALVES, H. RAPOSO, M. MAINARDES, E. W. O marketing no ensino superior: comparativo Brasil-Portugal. Revista de Administração Jornal FACES. 2010; p. 35-64. Disponível em: https://www.redalyc.org/articulo.oa?id=194018658003. Acesso em: is jun. 2020 .

BRASIL. Instituto Nacional de Estudos e Pesquisas Educacionais Anísio Teixeira INEP. . Pesquisas Estatísticas e Indicadores Educacionais: censo da educação superior. Censo da Educação Superior. 2019. Disponível em: https://www.gov.br/inep/pt$\mathrm{br} /$ areas-de-atuacao/pesquisas-estatisticas-e-indicadores/censo-da-educacaosuperior/resultados. Acesso em: 02 ago. 2021.

BOAVENTURA, P. S. M.; SOUZA, L. L. F. DE.; GERHARD, F.; BRITO, E. P. Z. (2018). Desafios na formação de profissionais em Administração no Brasil. Administração: Ensino E Pesquisa, v. I9, n. I, p. I-3I, 2018. Disponível em: https://doi.org/I0.13058/raep.2018.vigni.775. Acesso dia II de maio de 2021.

BRITO, L M; CASTRO, A. Descarte do conhecimento como estratégia de inovação: um estudo em uma instituição pública de educação não-formal do Nordeste do Brasil. HOLOS, v.30, n.4, p.397-414, 2014. Disponível em: http://www2.ifrn.edu.br/ojs/index.php/HOLOS/article/view/1214. Acesso em ro de maio de 2021.

CALAZANS, D. L. M.; SOUZA, W. J.; PEQUENO, N. P. F.; ARAÚJO, F. R.; LIMA JÚNIOR, V. Integrando a extensão universitária ao ensino e à pesquisa em Administração: sistematização de experiência junto a indígenas à luz dos Objetivos do Desenvolvimento Sustentável. Administração: Ensino E Pesquisa,v. 20, n. 3, p. 5636o8, 2019. Disponível em: https://doi.org/10.13058/raep.2019.v20n3.1505. Acesso dia ro de maio de 202I.

CAPES. Periodicos. 2005. Disponível em: https://www-periodicos-capes-govbr.ezl.periodicos.capes.gov.br/ . Acesso em: ro de maio de 2021.

COSTA, M.T. A experiência portuguesa no acesso a conteúdo académicos e científicos electrónicos: o caso da Biblioteca do Conhecimento On-Line (b-on). Revista Brasileira de Pós-Graduação, v. 7, n. 13, p. 250-260, 2010. Disponível em: https://www.researchgate.net/publication/31133827I_A_experiencia_portuguesa_no_a cesso_a_conteudos_academicos_e_cientificos_eletronicos_o_caso_da_Biblioteca_do_Co nhecimento_Online_b-on. Acesso o8 de maio de 2021. 
COSTA, A. S.; COSTA, R. O. S.; BERGAMO, F. V. M. Marketing de relacionamento em instituições educacionais: uma análise em instituição universitária. Revista formadores: vivências e estudos, v. 7, n. 2, p. 35-52, junho, 2014. Disponível em: https://seeradventista.com.br/ojs3/index.php/formadores/article/view/435/458. Acesso em o8 de maio de 202I.

DUARTE, A. S.; OliveirA, R. N.; PAIVA, T. B.; MORETTI, S. L. A.; OLIVEIRA, L. I. Expansão ilimitada do marketing no mercado estudantil - um estudo sobre a escolha dos alunos por cursos de graduação em uma instituição de ensino na cidade de São Paulo. Revista Brasileira de Pesquisas de Marketing, v. II, n. 2, p. 205-221, São Paulo, Maio-Agosto de 2018. Disponível em: http://www.revistapmkt.com.br/Portals/9/Revistas/viın2/6\%20-

\%20Expans\%C3\%A30\%2olimitada\%20do\%2oMarketing\%20no\%20mercado\%2oestud antil\%20-\%2oUm\%2oestudo\%20sobre\%20as\%2oescolhas\%2odos\%

20alunos\%2opor\%2ocursos\%2ode\%20Gradua\%C3\%A 7\%C3\%A30\%20em\%20uma\%20I ES\%2ona\%2ocidade\%2ode\%2oSP.pdf. Acesso em io de maio de 2021.

FIORILLO, A.; MACCARI, E. A.; MARTINS, C. B. A EAD no Brasil e a importância de competências subjacentes para o reconhecimento de cursos de acordo com a percepção de coordenadores de curso. Administração: Ensino E Pesquisa, v. I6, n. I, p. I4I-178, 2015. Disponível em: https://doi.org/ro.13058/raep.2015.vi6ni.211. Acesso dia II de maio de 202I

GOMES, Giancarlo; SILVEIRA, Amelia; SOUZA, Maria José Barbosa de. Plano de marketing: um olhar mais acurado sobre a adoção em instituições de ensino superior brasileiras. Revista Gestão Universitária na América Latina - Gual, v. 6, n. 2, p. 185209, abril, 2013. Universidade Federal de Santa Catarina (UFSC). http://dx.doi.org/10.5007/1983-4535.2013v6n2p185.

GUIMARÃES, J. C. F.; COUTINHO, C. V. S.; LAIN, G. C.; MILAN, G. S.; SEVERO, E. A. Inovação de marketing em instituições de ensino superior da serra gaúcha. Revista GUAL, v. 6, n. 2, p. 79-105, 2013. Disponível em: http://dx.doi.org/10.5007/1983-4535.2017vion2p43. Acesso em: I5 jun. 2021.

IMAGINÁRIO, S.; CRISTO, E.; JESUS, S. N.; M, F. A criação e gestão de miniempresas na sala de aula: opiniões dos alunos e professores participantes do programa empreender na escola. Avances em Psicologia Latino-americana, V.35, n. I, p. 23-43, 2017.

LINZMAYER, E. MINCIOTTI, S. A. Ações de marketing em instituições de ensino superior: um estudo na região do Grande ABC. Revista GUAL. v. Io, n. I, p. 43-70. Florianópolis, 2017. Disponível em: http://dx.doi.org/10.5007/1983-4535.2017vion2p43. Acesso em: is jun. 2021. 
MATTOS, A. M.; F. T. Portal periódicos Capes e os cursos de administração pública na Universidade Aberta do Brasil. Revista Brasileira de Pós-graduação, V.ıo, n. 19, p.117-134, 2013.

MIRAGAIA, D.; CARVALHO, P. Análise das metodologias de avaliação da empregabilidade dos Graduados em Desporto de Portugal. Jornal Motricidade, V. 8, n. $4, \quad$.26-38, Oct-Dec, 2012. Disponível em: https://www.redalyc.org/pdf/2730/273025193010.pdf. Acesso em II de maio de 202I

ROWE, D. E. O.; BASTOS, A. V. B.; PINHO, A. P. M. Comprometimento e entrincheiramento na carreira: um estudo de suas influências no esforço instrucional do docente do ensino superior. Rev. adm. contemp. [online], v.15, n. 6, p. 973-992, 2011. Disponível em: https://www.scielo.br/scielo.php?pid=S I4I5$65552011000600002 \& s c r i p t=s c i \_a b s t r a c t \& t \operatorname{lng}=p t$. Acesso dia II de maio de 2021.

SANTOS, V.; SANTOS, J. A. S. Redes sociais digitais e sua influência na sociedade e educação contemporâneas. HOLOS, v. 30, n. 6, p.307-328, 2014. Disponível em: http://www2.ifrn.edu.br/ojs/index.php/HOLOS/article/view/r936. Acesso em ıo de maio de 202I.

SOUZA, I. P. Percepções dos estudantes de graduação sobre o marketing educacional: um estudo no Instituto Federal de Educação, Ciência e Tecnologia de Mato Grosso Campus Cuiabá. 2020. Disponível em: http://hdl.handle.net/ro400.22/17679. Acesso em: 15 jun. 2020 .

SILVA, A. M. T.; LOURENÇO, M. L. O poder disciplinar enquanto dimensão da cultura organizacional: um estudo multicascos em instituições de ensino superior privadas. Administração: Ensino E Pesquisa, v. 19, n. I, 2018. Disponível em: https://raep.emnuvens.com.br/raep/article/view/73ı. Acesso dia io de maio de 2021.

TAKAHASHI, A.R.W. BULGACOV, S. SEMPREBON, E. GIACOMINI. M. M. (2017). Capacidades dinâmicas, capacidade de marketing e desempenho organizacional. Brazilian Business Review, I4(5), 466-478. Disponível em: http://dx.doi.org/ro.15728/bbr.2017.14.5.I. Acesso em: I5 jun. 2020.

VAle, M. P. E. DE M., Bertero, C. O., \& SilveirA, R. A. DA. Caminhos diferentes da americanização na educação em administração no brasil: a EAESP/FGV e a FEA/USP. Administração: Ensino E Pesquisa, v, I4, n. 4, p. 837-872, 2013. Disponível em: https://doi.org/I0.13058/raep.2013.vi4n4.49. Acesso dia o9 de maio de 2021. 